http://jmscr.igmpublication.org/home/ ISSN (e)-2347-176x ISSN (p) 2455-0450 crossref DOI: https://dx.doi.org/10.18535/jmscr/v7i7.79

\title{
Comarison of midazolam and ketamine versus propofol for procedural sedation during upper gastrointestinal endoscopy in children
}

\author{
Authors \\ Dr Pinky Gupta ${ }^{1}$, Dr Suryalata Kookna ${ }^{2}$, Dr Deepak Shivpuri ${ }^{3}$, Dr Sunil Dutt Sharma ${ }^{4}$, \\ Dr Lalit Bharadia ${ }^{5}$ \\ ${ }^{1}$ Senior Resident, Department of Pediatrics, Fortis Escort Hospital, Jaipur \\ ${ }^{2}$ Senior Resident, Department of Pediatrics, SMS Medical College and attached group of Hospitals, Jaipur, \\ ${ }^{3}$ Director \& Head of Department of Pediatrics and Neonatology, Surya Hospital, Jaipur \\ ${ }^{4}$ Pediatric Intensives, Surya Hospital, Jaipur \\ ${ }^{5}$ Pediatric Gastroenterologist, SDMH, Jaipur \\ Corresponding Author \\ Dr Suryalata Kookna
}

\begin{abstract}
Introduction: Gastrointestinal (GI) endoscopy has become an essential modality for evaluation and treatment of GI diseases. It is an unpleasant procedure and difficult to perform on conscious children. Conscious sedation has been widely accepted as primary sedation for children undergoing these procedures. This study compares the effectiveness, safety and adverse events with midazolam - ketamine combination versus propofol used for sedation.

Design: Hospital based observational comparative Study

Material and Methods: 150 children aged 1 year to 18 years of either sex who underwent UGE for diagnostic purposes at Fortis Escorts Hospital were included. All the Monitoring and resuscitative equipment were checked prior to the procedural sedation, These included SOAPME (suction, oxygen, airway, pharmacy, monitors and equipment). Patients were divided into group 1(midazolam-ketamine combination) and 2 (propofol). The effectiveness of the sedation, complications during the procedure and sedation and recovery time were recorded

Results: Significantly lower mean arterial pressure was observed in group 2 as compared to group1 till 10 minutes. No statistical significant difference was seen in respiratory rate and oxygen saturation during the procedure. Vomiting was significantly more in group 1 as compared to group $2(12 \% \mathrm{vs}$. 0\%) while stridor was more in group 2. No significant difference was observed in both the groups in bradycardia, apnea and Significant difference was observed in sensorium in both groups till 8 minutes duration whereas it was no significant at 10 minutes.

Conclusion: Procedural sedation is necessary during pediatric UGIE for analgesia, anxiolysis and amnesia. Propofol scored over midazolam + ketamine in terms of more rapid induction time, faster recovery and earlier discharge. Midazolam-ketamine scored over propofol in terms of less discomfort.
\end{abstract}

Keywords: UGIE, Midazolam, Ketamine, Propofol, Pediatrics.

\section{Introduction}

Gastrointestinal (GI) endoscopy has become an essential modality for evaluation and treatment of
GI diseases. The American Academy of Pediatrics (AAP) Committee on Drugs and The Joint Commission on Accreditation of Health Care 
Organizations (JCAHO) has published guidelines to ensure safety and to reduce the risks associated with sedation during endoscopic procedures ${ }^{1}$. General anesthesia is considered safe and effective in providing comfort and amnesia but requires expertise, special equipments and is not cost effective $^{2}$.

There are a number of procedural sedation regimens that have been reported to be safe and efficacious for children undergoing procedures. The most common sedation regimens used for pediatric endoscopy combine a narcotic analgesic (e.g. meperidine or fentanyl) with a benzodiazepine (e.g. diazepam or midazolam), although there have been increasing reports of the use of ketamine as an alternative agent. Narcotics offer the benefit of analgesia. Benzodiazepines provideanxiolysis and amnesia. Ketamine is reliable at rendering patients cooperative and comfortable $\mathrm{e}^{3,4}$.

Propofol is a rapid acting sedative agent with minimal recovery time ${ }^{5,6}$. It also has anti emetic and amnestic effect. Administration of propofol had been restricted primarily to anesthesiologists and nurse anesthetists trained in emergency airway management. There are however several papers on the administration of propofol by non anesthesiologists for gastroscopies in adults and a few reports on the administration of propofol in children $^{7,8,9}$.

The sedation regimen used by gastroenterologist in our unit is either intravenous (IV) midazolam ketamine combination or propofol for upper gastrointestinal endoscopy (UGIE). This study compare the efficacy of IV midazolam and ketamine (group 1) versus IV propofol (group 2) on the basis of hemodynamics (heart rate and systolic, diastolic and mean blood pressure), intra procedural sensorium [alert, verbal, pain, unresponsive scale (AVPU scale)], sedation time (time to achieve Ramsay Sedation Score), procedure time and recovery time (time to achieve Modified Aldrete Score 9) and adverse events in patients undergoing UGIE.

\section{Material and Methods}

Hospital based observational comparative analysis as Endoscopy Room, Gastroenterology Department, Fortis Escorts Hospital, Jaipur, Rajasthan from May 2014 to March 2015 Patients aged between $1-18$ years of either sex, belonging to ASA class $1 \& 2$ posted for UGIE at Fortis Escorts Hospital, Jaipur were selected for study after obtaining approval of the hospital ethics committee.

\section{Sample Size}

The sample size calculated is minimum 72 cases in each group at alpha error 0.05 and $80 \%$ power with Expected standard deviation within groups is 5.5 sec. to verify the observed in sedation score, mean difference of $2.6 \mathrm{sec}$. in both the groups (51.03 and 48.4 sec. respectively), observed in a pilot study conducted on 30 cases in each group at Fortis Hospital.

Age more than 18 years or below 1 year, impaired level of consciousness, not meeting fasting criteria, ASA physical status classification class III and above, patients with severe psychological problems such as cognitive or motor delay or severe behavioural problems, significant cardiac disease (angina, heart failure, malignant hypertension, recent significant head injury or reduced level of consciousness, intracranial hypertension with CSF obstruction, intra-ocular pathology (glaucoma, penetrating injury), previous psychotic illness, uncontrolled epilepsy were excluded.

An informed written consent was taken from each patient. 150 patients ASA I-II scheduled for UGIE were enrolled in the study. Parents who required sedation were informed about the benefits and risks of undergoing sedation, including the risk of respiratory adverse events and the necessity of emergency intubation.

The baseline data Demographic data and Indication for UGIE was recorded in a structured proforma. Pre-procedural assessment including general and systemic examination was done for all the patients according to the preset Performa.

Five personnel were present during the procedure.

- Pediatric Gastroenterologist for conducting endoscopy, 
- Technician for assistance during endoscopy

- Pediatric Intensivist trained in Pediatric life support

- Investigator (myself) for monitoring the sedation

- Nurse for assistance in sedation and monitoring

All the monitoring and resuscitative equipment were checked prior to the procedural sedation. These included SOAPME (suction, oxygen, airway, pharmacy, monitors, and equipment).

All vital parameters (HR/min, SBP in $\mathrm{mm} \mathrm{Hg}$, DBP in $\mathrm{mm} \mathrm{Hg}$ and MAP in $\mathrm{mm} \mathrm{Hg}, \mathrm{RR}$ and $\mathrm{SpO} 2$ ) were recorded. Venous access was taken on the non- dominant hand of each patient with $24 \mathrm{G}$ cannula. Period randomization was done. Initial 5 months (May to September 2014) children were included in groupland in the next 5 months (October to march2015) they were included in group 2.

(Group 1- Midazolam+ Ketamine, Group 2 Propofol, $\mathrm{N}=$ number)

\section{Group 1}

In this group children received IVmidazolam in the dose of $0.1 \mathrm{mg} / \mathrm{kg}$, diluted and given as a slow IV pushes over 1 minute. This was followed by IV ketamine in the dose of $1 \mathrm{mg} / \mathrm{kg}$ diluted with normal saline. Repeated smaller dosages of ketamine 0.5 $\mathrm{mg} / \mathrm{kg}$ were given as required, at intervals of 1 minute based on the patient's response until Ramsay Sedation Score (RSS) of 3-4 was reached.

\section{Group 2}

In this group, children received induction dose of Propofol $2 \mathrm{mg} / \mathrm{kg}$ slowly over 30 seconds. Repeated smaller dosages of $1 \mathrm{mg} / \mathrm{kg}$ were given based on the patient's response until RSS Score reached 3-4. The usual interval between boluses was 1 minute. Clear labelling of syringes containing drugs was done.

Subjects were followed from the point of selection until complete recovery.

All patients received supplemental oxygen via a nasal cannula (2 L/ min). The endoscopy was performed in the left lateral position. The following parameters were monitored and recorded:

- Vital parameters such as HR, SBP, DBP, $\mathrm{MAP}, \mathrm{RR}$ and $\mathrm{SpO} 2$ were recorded at 2 minute interval during procedure.

- Time to achieve Ramsay Sedation Score (RSS)(73)of 3-4 was recorded along with the total dose of drug needed.

- Level of sensorium by Alert Verbal Pain Unresponsive Scale (AVPU scale) to ascertain the adequate level of sedation reached during the procedure.

All the patients were monitored in recovery room till the criteria for discharge was met i.e. MAS>9.Pediatric Adverse effects if any were observed and recorded.

\section{Complications}

During the procedure and recovery following adverse events were monitored and treated accordingly.

- Hypoxia - $\mathrm{SpO} 2<92 \%$ for $>10 \mathrm{sec}$

- Bradycardia - $20 \%$ decrease in heart rate from baseline

- Hypotension - MAP < $20 \%$ decrease from baseline.

- Hypertension - MAP > 20\% increase from baseline

- Apnea - cessation of spontaneous respiration for 20 seconds

- Others such as vomiting, stridor

\section{Primary Outcome}

- Changes in Heart rate, Respiratory rate, blood pressure (systolic, diastolic and mean $\mathrm{BP})$ and $\mathrm{SpO} 2$ during UGIE

- Level of sensorium (AVPU scale)

- Time to achieve RSS score 3-4 (Sedation time)

- Achievement of MAS of 9 after completion of the procedure (Recovery time)

- Duration of UGIE (Procedure time) 


\section{Secondary Outcome}

- Complications during UGIE

- Complications during recovery

- Pain evaluation at start of procedure by using FPS

- Satisfaction level of Gastroenterologist, nurse, investigator

\section{Statistical Analysis}

Statistical analyses were done using computer software (SPSS version 20 and primer). The qualitative data were expressed in proportion and percentages and the quantitative data expressed as mean and standard deviations. The difference in proportion was analysed by using chi square test and the difference in means were analysed by using student $\mathrm{T}$ Test. Significance level for tests were determined as $95 \%(\mathrm{P}<0.05)$.

\section{Observation and Results}

Hemodynamics, sedation and recovery time, adverse events were compared between IV midazolam and ketamine combination (group 1) and IVpropofol (group 2).

In this study, no significant age and gender difference was observed in both the groups, females were $33.33 \%$ in group 1 whereas $36 \%$ in group 2.Mean weight in group 1 was $14.83 \pm 4.82(\mathrm{Kg})$ and in group 2 was $14.89 \pm 5.76(\mathrm{Kg}) . \mathrm{P}$ Value0.864

\section{Hemodynamic Data}

We compared the mean values of vitals at baseline, 2 minutes, 4 minutes, 6 minutes, 8 minutes and 10 minutes during procedure. No statistical significant difference was observed in baseline vitals in both groups. Significantly lower mean heart rate was observed in group 2 as compared to group 1 up to 10 minutes during the procedure. Significantly lower mean systolic blood pressure was observed in group 2 as compared to group1 up to 8 minutes while no significant difference at 10 minutes. Significantly lower mean DBP was observed in group 2 as compared to group1 till 8 minutes.

Significantly lower mean arterial pressure was observed in group 2 as compared to group1 till 10 minutes. No statistical significant difference was seen in respiratory rate and oxygen saturation during the procedure.

Group 2 had a significantly faster onset of action of 44.27 seconds when compared to group 1 of 56.45 seconds. No significant difference was observed in procedure time among the groups. $(\mathrm{P}=0.667)$ Significantly lower recovery time was observed in group $2(15.33 \pm 3.112 \mathrm{~min})$ as compared to group $1(24.67 \pm 3.002 \mathrm{~min})(\mathrm{P}<0.001 \mathrm{~S})$.

Vomiting was significantly more in group 1 as compared to group 2 (12\% vs. $0 \%)$ while stridor was more in group 2. No significant difference was observed in both the groups in bradycardia and apneaand. No significant difference was observed in case of hypotension .Significant difference was observed in sensorium in both groups till 8 minutes duration whereas it was no significant at 10 minutes.

Table No 1: Demographic Characteristics among the groups

\begin{tabular}{|l|c|c|c|c|c|}
\hline & \multicolumn{2}{|c|}{ Group 1(N=75) } & \multicolumn{2}{c|}{ Group 2(N=75) } & P Value LS \\
\hline Age (in months)(mean \pm sd) & 58.04 & 29.66 & 57.43 & 32.00 & $0.91 \mathrm{NS}$ \\
\hline Male & 50 & 66.67 & 48 & 64 & \multirow{2}{*}{$0.86 \mathrm{NS}$} \\
\hline Female & 25 & 33.33 & 27 & 36 & \\
\hline Weight $(\mathrm{Kg})($ mean \pm sd) & 14.83 & 4.82 & 14.89 & 5.76 & $0.95 \mathrm{NS}$ \\
\hline Baseline Parameters(mean $\pm \mathbf{s d})$ & & & & & \\
\hline HR & 109.33 & 9.4 & 108.31 & 12.04 & $0.56 \mathrm{NS}$ \\
\hline SBP & 106.44 & 7.21 & 106.05 & 7.72 & $0.752 \mathrm{NS}$ \\
\hline DBP & 69.2 & 5.23 & 68.91 & 7.1 & $0.774 \mathrm{NS}$ \\
\hline MAP & 81.52 & 5.03 & 79.96 & 6.72 & $0.11 \mathrm{NS}$ \\
\hline RR & 24.21 & 3.29 & 24.05 & 3.68 & $0.779 \mathrm{NS}$ \\
\hline SPO2 & 97.95 & 1.52 & 98.39 & 1.33 & $0.06 \mathrm{NS}$ \\
\hline
\end{tabular}


Table No 2: Vital Parameters among the groups

\begin{tabular}{|c|c|c|c|c|c|c|c|}
\hline \multicolumn{2}{|l|}{$\begin{array}{l}\text { Heart Rate } \\
\text { (per min) }\end{array}$} & Baseline & $2 \mathrm{~min}$ & $4 \mathrm{~min}$ & $6 \mathrm{~min}$ & $8 \min$ & $10 \mathrm{~min}$ \\
\hline \multirow{2}{*}{ Group 1} & Mean & 109.33 & 122.81 & 128.59 & 131.62 & 136.05 & 136 \\
\hline & SD & 9.4 & 8.97 & 14.24 & 11.33 & 7.57 & 2.83 \\
\hline \multirow{2}{*}{ Group 2} & Mean & 108.31 & 101.37 & 100.39 & 100.12 & 116.94 & 102 \\
\hline & SD & 12.04 & 9.98 & 8.65 & 8.32 & 7.72 & 2.83 \\
\hline P Value & & 0.561 & $<0.001$ & $<0.001$ & $<0.001$ & $<0.001$ & 0.007 \\
\hline \multicolumn{8}{|c|}{ Systolic BP (mm Hg } \\
\hline \multirow{2}{*}{ Group 1} & Mean & 106.44 & 112.39 & 119.69 & 120.62 & 120.59 & 121 \\
\hline & $\mathrm{SD}$ & 7.21 & 9.41 & 8.83 & 10.19 & 9.51 & 12.73 \\
\hline \multirow{2}{*}{ Group 2} & Mean & 106.05 & 96.52 & 96.33 & 96.21 & 95.46 & 101 \\
\hline & SD & 7.72 & 8.5 & 8.18 & 7.58 & 6.64 & 1.41 \\
\hline P Value & & 0.75 & $<0.001$ & $<0.001$ & $<0.001$ & $<0.001$ & 0.158 \\
\hline \multicolumn{8}{|c|}{ Diastolic BP (mm Hg) } \\
\hline \multirow{2}{*}{ Group 1} & Mean & 69.2 & 67.39 & 69.04 & 68.99 & 69.51 & 78 \\
\hline & SD & 5.23 & 5.73 & 6.19 & 6.43 & 5.14 & 0 \\
\hline \multirow{2}{*}{ Group 2} & Mean & 68.91 & 61.56 & 63.13 & 62.94 & 63.36 & 66 \\
\hline & SD & 7.1 & 5.75 & 4.1 & 4.17 & 3.92 & 0 \\
\hline P Value & & 0.774 & $<0.001$ & $<0.001$ & $<0.001$ & $<0.001$ & NA \\
\hline \multicolumn{8}{|c|}{ Mean Arterial Pressure $(\mathrm{mm} \mathrm{Hg})$} \\
\hline \multirow{2}{*}{ Group 1} & Mean & 81.52 & 82.33 & 85.79 & 86.22 & 86.44 & 92 \\
\hline & SD & 5.03 & 4.844 & 5.207 & 5.511 & 4.855 & 4.243 \\
\hline \multirow{2}{*}{ Group 2} & Mean & 79.96 & 73.16 & 74.2 & 73.83 & 73.97 & 77.5 \\
\hline & SD & 6.72 & 5.62 & 3.8 & 3.67 & 3.31 & 0.71 \\
\hline P Value & & 0.11 & $<0.001$ & $<0.001$ & $<0.001$ & $<0.001$ & 0.041 \\
\hline \multicolumn{8}{|c|}{ Respiratory rate (per min) } \\
\hline \multirow{2}{*}{ Group 1} & Mean & 24.21 & 23.8 & 24.17 & 24.05 & 23.67 & 22 \\
\hline & SD & 3.29 & 3.42 & 2.79 & 2.455 & 2.718 & 0 \\
\hline \multirow{2}{*}{ Group 2} & Mean & 24.05 & 23.64 & 23.53 & 23.36 & 23.11 & 24 \\
\hline & SD & 3.68 & 2.97 & 2.21 & 2.315 & 1.737 & 0 \\
\hline P Value & & 0.779 & 0.76 & 0.121 & 0.08 & 0.29 & NA \\
\hline \multicolumn{8}{|l|}{ SPO2 (\%) } \\
\hline \multirow{2}{*}{ Group 1} & Mean & 97.95 & 97.52 & 98.25 & 98.75 & 98.9 & 99.5 \\
\hline & SD & 1.52 & 2.21 & 1.96 & 1.14 & 1.12 & 0.71 \\
\hline \multirow{2}{*}{ Group 2} & Mean & 98.39 & 98.47 & 98.27 & 98.46 & 98.89 & 96 \\
\hline & SD & 1.33 & 1.49 & 1.96 & 1.7 & 0.98 & 2.83 \\
\hline P Value & & 0.06 & 0.003 & 0.96 & 0.22 & 0.97 & 0.23 \\
\hline Significance & & NS & $\mathrm{S}$ & NS & NS & NS & NS \\
\hline
\end{tabular}

Table No 3: Quantitative Parameters among the groups

\begin{tabular}{|l|c|c|c|c|c|}
\hline & \multicolumn{2}{|c|}{ Group 1 } & \multicolumn{2}{c|}{ Group 2 } & \\
\hline & Mean & SD & Mean & SD & P Value LS \\
\hline Sedation time (seconds) & 51.03 & 4.32 & 48.4 & 5.59 & $<0.001 \mathrm{~S}$ \\
\hline Procedure time (Minutes) & 7.09 & 1.13 & 7.01 & 1.15 & $0.667 \mathrm{NS}$ \\
\hline Recovery Time min & 24.67 & 3.00 & 15.33 & 3.11 & $<0.001 \mathrm{~S}$ \\
\hline
\end{tabular}


Table no 4: Satisfaction Levels in 2 groups

\begin{tabular}{|c|c|c|c|c|c|c|}
\hline & \multicolumn{2}{|c|}{ Gastroenterologist } & \multicolumn{2}{|c|}{ Investigator } & \multicolumn{2}{|c|}{ Nurse } \\
\hline & $\begin{array}{c}\text { Not } \\
\text { satisfied }\end{array}$ & Satisfied & $\begin{array}{c}\text { Not } \\
\text { satisfied }\end{array}$ & Satisfied & $\begin{array}{c}\text { Not } \\
\text { satisfied }\end{array}$ & Satisfied \\
\hline Group 1 & 0 & $75(100)$ & 0 & $75(100)$ & 0 & $75(100)$ \\
\hline Group 2 & $\begin{array}{c}46 \\
(61.33) \\
\end{array}$ & $\begin{array}{c}29 \\
(38.67) \\
\end{array}$ & $\begin{array}{c}46 \\
(61.33) \\
\end{array}$ & $\begin{array}{c}29 \\
(38.67) \\
\end{array}$ & $\begin{array}{c}46 \\
(61.33) \\
\end{array}$ & $\begin{array}{c}29 \\
(38.67) \\
\end{array}$ \\
\hline$P$ value & \multicolumn{2}{|c|}{$<0.001 \mathrm{~S}$} & \multicolumn{2}{|c|}{$<0.001 \mathrm{~S}$} & \multicolumn{2}{|c|}{$<0.001 \mathrm{~S}$} \\
\hline
\end{tabular}

Table No 5: Intraprocedural Sensorium at 2 minutes

\begin{tabular}{|c|c|c|c|c|c|c|c|}
\hline & & $\mathrm{N}$ & Alert & Verbal & Pain & unresponsive & $\mathrm{P}$ value \\
\hline \multirow[b]{2}{*}{$2 \mathrm{MIN}$} & Group 1 & 75 & 0 & $61(81.3)$ & 14 (18.7) & 0 & \multirow{2}{*}{$<0.001$} \\
\hline & Group 2 & 75 & 0 & 74 (98.7) & $1(1.3)$ & 0 & \\
\hline \multirow{2}{*}{$4 \mathrm{~min}$} & Group 1 & 75 & 0 & $28(37.3)$ & $46(61.3)$ & $1(1.33)$ & \multirow{2}{*}{$<0.001$} \\
\hline & Group 2 & 75 & 0 & $57(76.0)$ & $15(20.0)$ & $3(4.0)$ & \\
\hline \multirow{2}{*}{ 6min } & Group 1 & 73 & 0 & $22(30.14)$ & $47(64.38)$ & $4(5.48)$ & \\
\hline & Group 2 & 72 & 0 & $54(75.00)$ & $15(20.83)$ & $3(4.17)$ & \\
\hline \multirow{2}{*}{$8 \mathrm{~min}$} & Group 1 & 39 & 0 & $16(41.03)$ & $20(51.28)$ & $3(7.69)$ & \multirow{2}{*}{0.04} \\
\hline & Group 2 & 36 & 0 & $25(69.44)$ & $9(25.00)$ & $2(5.56)$ & \\
\hline \multirow{2}{*}{$10 \mathrm{~min}$} & Group 1 & 2 & 0 & 0 & $1(50.0)$ & $1(50.0)$ & \multirow{2}{*}{0.13} \\
\hline & Group 2 & 2 & 0 & 0 & 0 & $2(100.00)$ & \\
\hline
\end{tabular}

Table No 6: Hypotension among the groups

\begin{tabular}{|l|c|c|c|c|c|c|}
\hline Hypotension & \multicolumn{2}{|c|}{ Group 1 } & \multicolumn{2}{c|}{ Group2 } & Total & P Value LS \\
\hline & $\mathrm{N}$ & $\%$ & $\mathrm{~N}$ & $\%$ & & \\
\hline $2 \mathrm{~min}$ & 0 & 0 & 0 & 0 & 0 & NA \\
\hline $4 \mathrm{~min}$ & 0 & 0 & 4 & 5.3 & 4 & $0.12 \mathrm{NS}$ \\
\hline $6 \mathrm{~min}$ & 0 & 0 & 0 & 0 & 0 & NA \\
\hline $8 \mathrm{~min}$ & 0 & 0 & 2 & 2.7 & 2 & $0.47 \mathrm{NS}$ \\
\hline $10 \mathrm{~min}$ & 0 & 0 & 0 & 0 & 0 & NA \\
\hline
\end{tabular}

Table No 7: Complications among the groups

\begin{tabular}{|l|c|c|c|c|c|c|c|}
\hline & \multicolumn{2}{|c|}{ Group 1 (N=75) } & \multicolumn{2}{|c|}{ Group 2 (N=75) } & \multicolumn{2}{|c|}{ Total } & P Value \\
\hline & $\mathrm{N}$ & $\%$ & $\mathrm{~N}$ & $\%$ & $\mathrm{~N}$ & $\%$ & Significance \\
\hline Vomiting & 9 & 12 & 0 & 0 & 9 & 6 & $0.006 \mathrm{~S}$ \\
\hline Hypoxia & 0 & 0 & 0 & 0 & 0 & 0 & $\mathrm{NA}$ \\
\hline Stridor & 0 & 0 & 29 & 38.67 & 29 & 19.33 & $<0.001 \mathrm{~S}$ \\
\hline Bradycardia & 0 & 0 & 1 & 1.33 & 1 & 0.67 & $1.0 \mathrm{NS}$ \\
\hline Apnea & 0 & 0 & 1 & 1.33 & 1 & 0.67 & $1.0 \mathrm{NS}$ \\
\hline
\end{tabular}

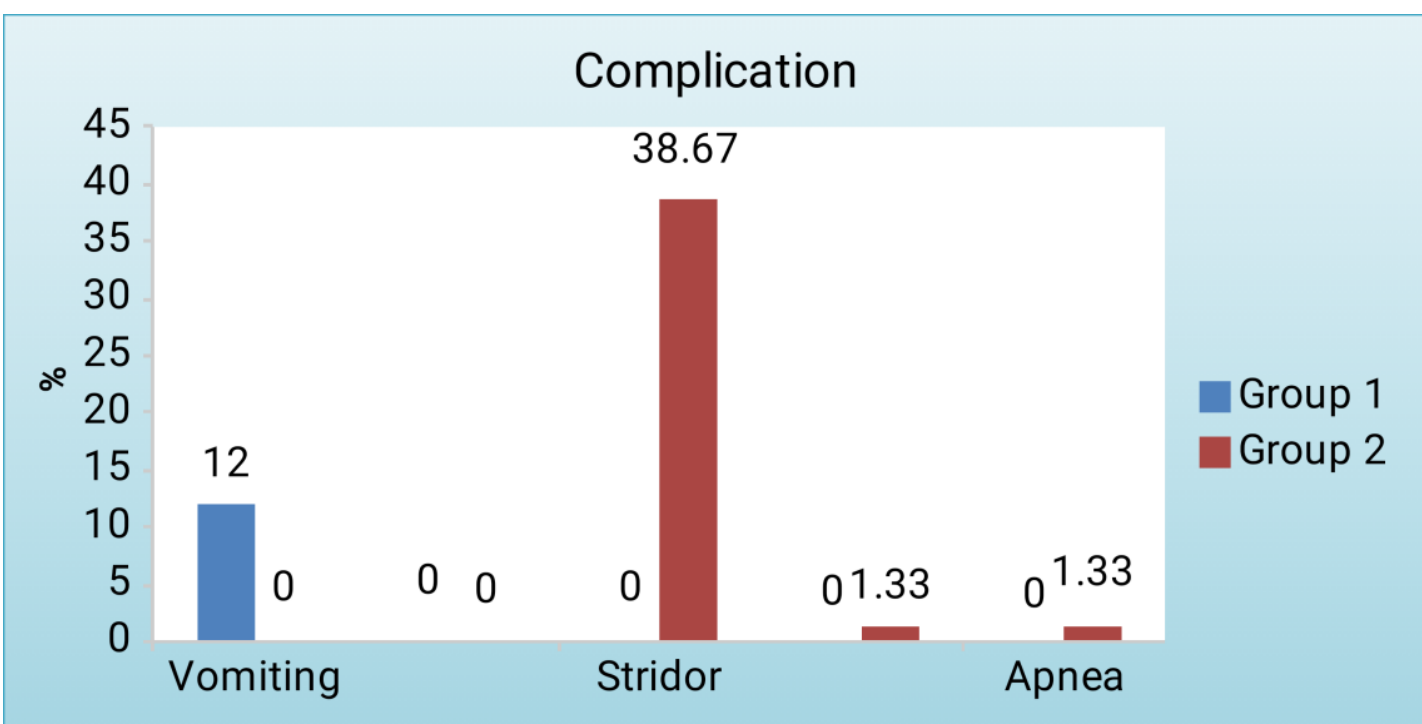




\section{Discussion}

Endoscopic procedures for diagnostic and therapeutic purposes in children are increasing. However there are no clear guidelines for the procedural sedation of choice. This study compares effectiveness, safety and hemodynamics during procedural sedation between two groups (group 1 using IVmidazolam and ketamine and group 2 using IVpropofol) for sedation in UGIE. 150 patients ASA I-II posted for elective diagnostic UGIE procedures that fulfilled the inclusion criteria were enrolled in the study. In our study demographic data was comparable between the studied groups.

\section{Dose}

Group 1 received midazolam $0.1 \mathrm{mg} / \mathrm{kg}$ with ketamine $1 \mathrm{mg} / \mathrm{kg}$ at the beginning of procedure with additional doses of ketamine $0.5 \mathrm{mg} / \mathrm{kg}$. Group 2 received propofol at loading dose of $2 \mathrm{mg} / \mathrm{kg}$ over 30 seconds with additional doses of $1 \mathrm{mg} / \mathrm{kg}$.

The dose regimen of propofol used by JiEun Oh et $\mathrm{al}^{10}$ was similar to our study. In their study, propofol was used with an induction dose of $2 \mathrm{mg} / \mathrm{kg}$ in children up to 8 years of age and 1 to $2 \mathrm{mg} / \mathrm{kg}$ in older children. Repeated smaller dosages of 0.5 to 1 $\mathrm{mg} / \mathrm{kg}$ were given to maintain sedation based on the patient's response at 1 minute interval.

We used dose of midazolam - ketamine similar to study done by BorkerA et $\mathrm{al}^{11}$ for procedural sedation in pediatric hematology-oncology unit. Parker RI et $\mathrm{al}^{12}$ also used similar doses of midazolam - ketamine as we used in our study.

\section{Primary Outcome}

In our study sedation time, recovery time, hemodynamic variables associated with the use of propofol were compared with those associated with the use of midazolam-ketamine during UGIE.

Heart Rate and Mean Arterial pressure

In our study children in group 2 had significantly ( $\mathrm{p}$ $<0.05)$ lower heart rates at 2, 4, 6, 8 and 10 minutes than in group 1. These results are in accordance with previous study by JiEun $\mathrm{Oh}$ et $\mathrm{al}^{10}$ who reported that after administration of propofol, heart rate was significantly decreased during procedure as compared to midazolam.
MAP was significantly lower in group 2 than in group 1. This is similar to the study done by Shrivastav et $\mathrm{al}^{13}$ who compared addition of Ketamine, midazolam, Propofol or saline to propofol as acoinduction in elective orthopaedic operations and concluded that ketamine had additional advantage of better hemodynamic stability.

Similar results are seen in study done by Khutia et $\mathrm{al}^{14}$ who compared infusion of propofol - ketamine with propofol- fentanyl and found that HR and MAP were significantly decreased in Propofolfentanyl group, probably reflecting stable hemodynamics with addition of ketamine to propofol.

In contrast another study conducted by Tosun et al ${ }^{15}$ that compared addition of propofol and ketamine with propofol and fentanyl in pediatric patients who underwent burn dressing, demonstrated that HR, MAP were comparable in both groups. This difference may be because induction dose of propofol, ketamine and fentanyl were different from the doses used in our study.

\section{Respiratory rate and Oxygen Saturation}

All patients in our study maintained normal oxygen saturation levels throughout the procedure. This may be due to that all of them received supplemental oxygen via nasal prongs at $21 / \mathrm{min}$.

Respiratory rate was also comparable in both studied groups.

\section{Sensorium}

In our study intra procedural sensorium was assessed by AVPU scale. It was observed that patients in group 2 continued to be verbally responsive at 2,4,6,8 minutes as compared to group 1 indicating less progression to deeper level of sedation in group 2. However at 10 minutes deep sedation was achieved in both groups with no statistical significance.

\section{Sedation time, Recovery time, Procedure time}

Our study showed that the recovery time and sedation time were significantly shorter in group 2 
$(15.33 \pm 3.112)$ as compared to group 1(24.67 \pm $3.002 \mathrm{~min}$ ) which is similar to the study done byMiner et al $^{16}$ who compared propofol with ketamine (as a single drug) and reported a significantly shorter recovery time with propofolwith a high rate of recovery agitation (emergence phenomena) with ketamine.

Godambe et al $^{17}$ reported recovery time of fifty-four minutes following sedation with midazolam/ketamine $(0.04$ and $1.99 \mathrm{mg} / \mathrm{kg}$, respectively) and of twenty minutes following sedation with propofol/fentanyl $(4.55 \mathrm{mg} / \mathrm{kg}$ and $1.21 \mathrm{mcg} / \mathrm{kg}$, respectively) in children.

JiEun Oh et al $^{10}$ reported shorter recovery time $(30 \pm 16.41 \mathrm{~min})$ in propofol group as

MachataA.M. et $\mathrm{al}^{18}$ found median induction time was $2(1,2)$ min, sedation time $55(45,65) \mathrm{min}$, and recovery time $8(8,9) \mathrm{min}$ in children receiving propofol for magnetic resonance imaging.

Havel et $\mathrm{al}^{19}$ found recovery time in propofol group $14.9 \pm 11.1$ minutes, compared with $76.4 \pm 47.5$ minutes in midazolam group.

The recovery time in our study was shorter perhaps because of the administration of lower sedative doses, shorter procedure time and different criteria used for recovery time. We preferred to avoid infusion because smaller and slower boluses of propofol may reduce adverse events. The mean dose of propofol in our study was $3.2 \mathrm{mg} / \mathrm{kg}$.

\section{Procedure time}

Duration of UGIE procedure was comparable in both the groups $(p=0.667)$. It was $7.09 \pm 1.129$ minutes in group 1 and $7.01 \pm 1.145$ minutes in group 2. This was similar to study done by JiEun Oh et al(13)who recorded average duration of endoscopic procedures $7.71 \pm 2$ minutes in Midazolam group and $8.21 \pm 3.26$ minutes in propofol group $(\mathrm{P}=0.757)$.

\section{Secondary Outcome}

\section{Adverse events}

None of our patient in either study group experienced significant adverse events during the procedure. Only one patient had apnea and bradycardia just after procedure (during recovery) and required bag and mask ventilation for 30 seconds. Because the study was not powered to examine differences in the rates of adverse events, we were not able to determine the significance of this difference, and larger studies are required for further examination of the safety of these interventions.

The main difference in regard to safety was that patient in group 2 had demonstrated transient reversible decrease in their MAP but none of them required treatment for hypotension. This was similar to study done by Vardi A et $\mathrm{al}^{20}$ who compared propofol alone with ketamine, midazolam and fentanyl combination and recorded transient fall in BP. Propofol exerts this effect due to vasodilator properties, reduced cardiac contractility and negative chronotropic effects.

In our study, 29 patients (38.67\%) in propofol group had stridor which was mild and resolved spontaneously, suggesting that the benefits may still outweigh the risks. This relatively low prevalence of serious adverse events is encouraging and suggests that procedural sedation with use of either a propofol or a midazolam/ketamine regimen can be safely implemented by specifically trained non anesthesiologists. Nevertheless, it must be emphasized that the therapeutic index is narrower for propofol than it is for midazolam/ ketamine because of the potential risk of serious adverse events. Therefore, propofol should only be administered by those who are capable of performing an emergency endotracheal intubation if needed and a crash cart and intubation kit should be available when propofol is used.

Disma $\mathrm{N}$ et $\mathrm{al}^{21}$ compared propofol sedation with fentanyl or midazolam during EGD in children and found less incidence of side effects in propofolmidazolam and propofol-fentanyl than in propofol alone. Apnea requiring bag and mask ventilation was found in 2 patients receiving propofol alone $(\mathrm{n}=$ $80)$ and 2 in propofol-fentanyl group $(n=82)$, and none in propofol- midazolam group $(n=78)$. Laryngeal spasm (stridor) was found in 3 patients in propofol alone group, not in other 2 groups. Jayabose et $\mathrm{al}^{(22)}$ concluded in their study that 
hypoxia was rare and never enough to warrant intubation in propofol based anesthesia.

In our study $9(12 \%)$ developed vomiting in midazolam- ketamine group which was similar to study done by Wathen JE et al(23)who found vomiting in $9.6 \%$ patients due to midazolam ketamine during procedural sedation in children.

Similarly Roback MG et $\mathrm{al}^{23}$ found vomiting in $10.1 \%$ patients in ketamine alone group, in $5.4 \%$ with ketamine -midazolam group and in $1.8 \%$ with midazolam- fentanyl and only $0.8 \%$ with midazolam alone group.

Squires and colleagues (2) reported that inhalational anaesthesia increased the total cost of upper gastrointestinal endoscopy in children more than IV. Anaesthesia and that the use of inhalational anaesthesia was associated with a greater risk of complications. In our study, we performed all paediatric endoscopies in the endoscopy unit; Operating room was kept ready for any untoward adverse events or risk of respiratory problems.

\section{Conclusion}

The main findings in our study are:

- Both regimens (Midazolam + Ketamine and propofol) may be safely used for outpatient endoscopies by non anesthesiologists.

- Propofol scored over midazolam + ketamine in terms of more rapid induction time, faster recovery and earlier discharge.

- Midazolam-ketamine scored over propofol in terms of less discomfort and greater satisfaction of gastroenterologist.

- Staff performing procedures must be adequately trained not only to give sedation smoothly but also to handle any cardio respiratory emergencies if they occur.

\section{Recommendation}

Procedural sedation is necessary during pediatric UGIE for analgesia, anxiolysis and amnesia. For a successful and safe sedation, physicians and all staff members should be sufficiently trained and educated and should follow the standardized guideline from preparation of sedation to discharge

\section{Limitations}

Our study was a single centre study with small sample size where blinding was not done.

\section{References}

1. Ralph E. Kauffman WB, Cheston M. Berlin, Jeffrey L. blumer. American Academy of Pediatrics Committee on Drugs: Guidelines for monitoring and management of pediatric patients during and after sedation for diagnostic and therapeutic procedures. Pediatrics. 1992 June;89(6):1110-5.

2. Squires RH Jr MF, Schluterman S, Drews B, Galyen L, Brown KO Efficacy, safety, and cost of intravenous sedation versus general anesthesia in children undergoing endoscopic procedures. GastrointestEndos. 1995;41(2):99-104.

3. Tolia V PJ, Gilger MA. Sedation for pediatric endoscopic procedures. J PediatrGastroenterolNutr. 2000;30(5):47785.

4. Lightdale JR MP, Fredette ME. A pilot study of ketamine versus midazolam/ fentanyl sedation in children undergoing GI endoscopy. Int J Pediatr. 2011;2011:110-6.

5. Vargo JJ DM, Feld AD Multisociety sedation curriculum for gastrointestinal endoscopy. Gastrointest Endosc. 2012;76(1): 1-25.

6. Lightdale JR VC, Newburg AR, Mahoney LB, Zgleszewski S, Fox VL Efficiency of propofol versus midazolam and fentanyl sedation at a pediatric teaching hospital:A prospective study GastrointestEndosc 2008;67(7):1067-75.

7. Thakkar K E-SH, Mattek N, Gilger MA Complications of pediatric EGD: a 4-year experience in PEDS-CORI. Gastrointest Endosc. 2007;65(2):213-21.

8. Ament $\mathrm{ME} \mathrm{CD}$. Upper gastrointestinal fiberoptic endoscopy in pediatric patients. Gastroenterology. 1977;72(6):1244-8.

9. Gilger MA JS, Barrish JO, McCarroll LR. Oxygen desaturation and cardiac 
arrhythmias in children during esophagogastroduodenoscopy using conscious sedation GastrointestEndosc 1993;39(3):392-5.

10. JiEun Oh HJLaYHL. Propofol versus Midazolam for Sedation during Esophagogastroduodenoscopy in Children. ClinEndosc. 2013 July;46(4):368-72

11. AnupamaBorker IA, R. Gopal and S.H. Advani Safe and Efficacious Use of Procedural Sedation and Analgesia by NonAnesthesiologists in a Pediatric Hematology-Oncology Unit. Indian Pediatrics. 2006;43(5):309-14.

12. Parker RI MR, Giugliano D, Parker MM. Efficacy and safety of intravenous midazolam and ketamine as sedation for therapeutic and diagnostic procedures in children. Pediatrics. 1997 Mar;99(3):427-31.

13. Srivastava U SN, Kumar A, Saxena S. Small dose propofol or ketamine as an alternative to midazolam co-induction to midazolam. Indian J Anaesth 2006;50(2):112-4.

14. S K Khutia MM, S Das, SR Basu. Intravenous infusion of ketamine propofol can be an alternative to intravenous infusion of fentanyl - propofol for deep sedation and analgesia in paediatric patients undergoing emergency short surgical procedures. Indian J Anaesth. 2012;56(4):145-50.

15. Tosun $\mathrm{Z}$ EA, Coruh A. Propofol ketamine vspropofol _ fentanyl combinations for deep sedation and analgesia in pediatric patients undergoing burn dressing changes. PaediatrAnaesth. 2008;18(5):43-78.

16. Miner JR GR, Bahr J, Patel R, McGill JW. Randomized clinical trial of propofol versus ketamine for procedural sedation in the emergency department. AcadEmerg Med. 2010 Jun;17(6):604-11.
17. Godambe- Godambe SA EV, Matheny D, Pershad J. Comparison of propofol/fentanyl versus ketamine/midazolam for brief orthopedic procedural sedation in a pediatric emergency department. Pediatrics. 2003;112(1):116-23.

18. A.-M. Machata HW, B. Kabon. Propofolbased sedation regimen for infants and children undergoing ambulatory magnetic resonance imaging. British Journal of Anaesthesia. 2008 June;101(2):239-43.

19. Havel CJ Jr SR, Hennes H. A clinical trial of propofolvs midazolam for procedural sedation in a pediatric emergency department. AcadEmerg Med. 1999 Oct;6(10):989-97.

20. Vardi A SY, Padeh S, Paret G, Barzilay Z. Is propofol safe for procedural sedation in children? A prospective evaluation of propofol versus ketamine in pediatric critical care. Crit Care Med. 2002 Jun;30(6):1231-6.

21. N. Disma MA, G. Rizzo. Propofol sedation with fentanyl or midazolam during oesophagogastroduodenoscopy in children European Journal of Anaesthesiology. 2005;22(11):848-52.Jayabose S L-TO, Giamelli J, et al. Intravenous anesthesia with propofol for painful procedures in children with cancer. J PediatrHematolOncol 2001 Jun-Jul;23(5):290-3.

22. Jayabose S L-TO, Giamelli J, et al. Intravenous anesthesia with propofol for painful procedures in children with cancer. $\mathbf{J}$ Pediatr Hematol Oncol 2001 JunJul;23(5):290-3.

23. Wathen JE RM, Mackenzie T, Bothner JP. Does midazolam alter the clinical effects of intravenous ketamine sedation in children? A double-blind, randomized, controlled emergency department trial. Ann Emerg Med. 2000 Dec;36(6):579-88. 